PAPERS

\title{
Optimization of surface-mounted permanent magnet brushless AC motor using analytical model and differential evolution algorithm
}

\author{
Mohd Rezal Mohamed*, Dahaman Ishak ${ }^{* *}$
}

\begin{abstract}
This paper discusses the optimization of surface-mounted permanent magnet brushless AC (PMBLAC) motor using Analytical Sub-domain model with Differential Evolution Algorithm (ASDEA). Only two regions were considered in this analytical sub-domain model, ie magnet and airgap regions, with assistance of Complex Relative Permeance Function (CRPF) to account for the stator slotting effect. Five machine parameters were chosen to be optimized, namely the magnet arc-pole-pitch ratio, slot opening width, magnet thickness, airgap length and stator inner radius. The optimization process has four objectives, ie minimum torque ripple, low cogging torque, high efficiency, and high output torque. The results from the optimized ASDEA were compared with the Analytical Sub-domain Genetic Algorithm (ASGA) and further validated against 2-D finite element model (FEM). Results show a good agreement between analytically optimized models and finite element model. The ASDEA has faster computational time compared to ASGA, and this provides benefit in terms of reducing the machine design parameterization time and less redundancy work required to achieve motor design specifications.
\end{abstract}

K e y w ords: analytical sub-domain, differential evolution, permanent magnet, brushless motor

\section{Introduction}

The automotive and mechatronics industries normally require electric machines with high-torque density, high efficiency and/or wide-speed range of power capability. One of the electric machines that exhibit good performance characteristics is the permanent magnet brushless $\mathrm{AC}$ machine (PMBLAC) [1]. Even though PMBLAC is the best candidate, it still has few design concerns such as the torque ripple, cogging torque and rotor eddy current losses, which can affect the overall machine performance [2]. Usually, electric machine designerswould apply the finite element analysis (FEA) to design and model an electric machine. This approach can usually produce good results, but it has longer computational time which leads to longer time frame for machine design. Besides FEA, analytical sub-domain model (ASDM) has gained popularity among the researchers to model and predict the machine performance. ASDM which is based on Laplaces and Poissons equations governed in the machine domains has been tested with much success for surface-mounted PMBLAC and inset PMBLAC, either internal or external rotor topologies. However, obtaining optimized machine parameters in ASDM can be considered as manual trial-and-error method based on previous data, user experience and intuition. For example, machine parameters such as magnet thickness, stator tooth width, slot opening width, and air gap length, are interdependent and related, and they can greatly affect the motor performance. This shortcoming, however, might be resolved using optimization tools available in the commercial FEA software, but its price is relatively expensive and it has limited features too. Due to this concern, in this paper, analytical sub-domain model was selected due to its fast computational time and then integrated with a multi-objective differential evolution algorithm to optimize PMBLAC parameters. The optimization objectives are to have low total harmonic distortion of phase back-emf, low cogging torque, high output torque, and high efficiency. Ideally, low total harmonic distortion of phase back-emf will lead to reduced torque ripple. Consequently after optimization process, the cost of electric machine would potentially become lower due to smaller volume of active materials used for the magnets and steel cores. This research has a lot of significance to the industry such as to accelerate the design stage with optimized PMBLAC parameters before moving to the fabrication stage and to minimize the design cost by reducing active material volume of PMBLAC using a low-cost optimization tool. In this paper, the research work has two main parts. The first part explains the surface-mounted PMBLAC modelling using analytical sub-domain. Whereas, the second part employs the optimization technique by evolutionary computing which is considered as a multi-objective Differential Evolution Algorithm. The constructions of PMBLAC can be divided into three important components, ie stator core, rotor core and motor winding. The rotor core can either be internal or external type, while the motor winding can be concentrated or distributed winding type. Internal rotor of PMBLAC can accommodate the permanent magnet materials such as surface-mounted, inset and interior permanent magnet. Different internal rotor types will have

*Universiti Kuala Lumpur, Malaysian Spanish Institute, Kulim, Kedah, Malaysia, **School of Electrical and Electronic Engineering, Engineering Campus, Universiti Sains Malaysia, Penang, Malaysia, dahaman@usm.my 


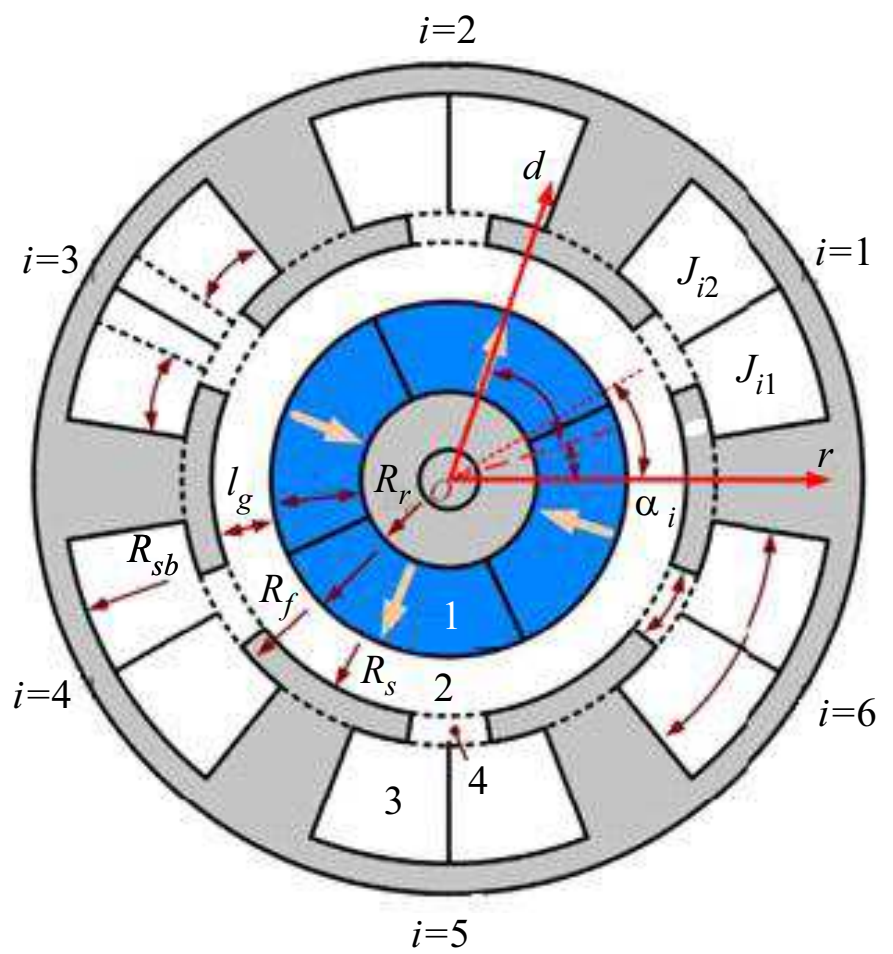

Fig. 1. PMBLAC sub-domain [15]: 1 - permanent magnet, 2 - air-gap, 3 - slot opening, 4 - winding slot

different magnetic characteristics due to the magnet location in the rotor core. Surface-mounted internal rotor type is often preferred due to smallest leakage flux. PMBLAC with concentrated winding type has better efficiency and lower cost due to less copper and magnetic volume used [3-5]. The magnetization vectors in the rotor magnets can either be radial, parallel, or Halbach patterns. Due to ease of modeling in analytical sub-domain model and fabrication, the radial magnetization pattern was chosen for the magnet in this research work. PMBLAC has fractional slot due to its slot/pole ratio. In general, PMBLAC can be modeled using three modeling techniques, namely analytical model, magnetic equivalent circuit (MEC), and finite element analysis (FEA) [6, 9]. The analytical model has the shortest computational time compared to MEC and FEA models, whereas MEC is computationally shorter than FEA [7, 9]. FEA has the longest computational time, but highest torque accuracy and magnetic loss estimation, as well as better design flexibility $[8,9]$. Despite the advantage of computational effort, the analytical model has few disadvantages such as less accuracy, less flexible compared to FEA, and incapable of 3-D effect. It is suitable to analyse a $2-\mathrm{D}$ design with less complexity in the design $[7]$.

\section{Analytical sub-domain modelling}

Analytical sub-domain model applies separation of variable technique using 2-D Laplace equation for the air gap and slot opening regions, while 2-D Poisson equation is used for the magnet and winding slot regions [10]. The armature reaction and slot mutual influence can also be determined using this analytical sub-domain model [10]. The open-circuit and on-load parameters can also be included $[11,12]$. The magnetic field distribution, phase back-emf, electromagnetic torque, and winding inductance are then predicted in this model [10-14]. The common formulae for analytical sub-domain model using magnetic vector potential in the permanent magnet $\left(A_{z 1}\right)$, air-gap $\left(A_{z 2}\right)$, winding slots $\left(A_{z 3 i}\right)$, and slotopenings $\left(A_{z 4 i}\right)$ in $2-\mathrm{D}$ polar coordinates are described in (1) to (4) [15]. $M_{\mathrm{r}}$ and $M_{\alpha}$ are the radial and circumferential components of magnet magnetization, while $J$ is the current density in stator slot, and ${ }_{0}$ is the relative permeability. Regions of PMBLAC are divided into four sub-domains, ie the permanent magnet region, air-gap region, slot opening region, and the winding slot region as shown in Fig. 1, [15]. Few assumptions were used in this modelling, namely infinite permeability in the rotor and stator cores; no electrical conductivity in the rotor and stator cores; the eddy current reaction field was neglected (resistance limited approximation); the teeth were spoke shaped (radial slot boundaries); end effect was neglected; and linear magnet properties

$$
\begin{gathered}
\frac{\partial^{2} A_{z 1}}{\partial r^{2}}+\frac{1}{r^{2}} \frac{\partial A_{z 1}}{\partial r}+\frac{\partial^{2} A_{z 1}}{\partial \alpha^{2}}=-\frac{\mu_{0}}{r}\left(M_{\alpha}-\frac{\partial M_{r}}{\partial_{\alpha}}\right) \\
\frac{\partial^{2} A_{z 2}}{\partial r^{2}}+\frac{1}{r^{2}} \frac{\partial A_{z 2}}{\partial r}+\frac{\partial^{2} A_{z 2}}{\partial \alpha^{2}}=0 \\
\frac{\partial^{2} A_{z 3}}{\partial r^{2}}+\frac{1}{r^{2}} \frac{\partial A_{z 3}}{\partial r}+\frac{\partial^{2} A_{z 3}}{\partial \alpha^{2}}=-\mu_{0} J \\
\frac{\partial^{2} A_{z 4}}{\partial r^{2}}+\frac{1}{r^{2}} \frac{\partial A_{z 4}}{\partial r}+\frac{\partial^{2} A_{z 4}}{\partial \alpha^{2}}=0
\end{gathered}
$$




$$
\begin{aligned}
& B_{s r I}(r, \theta)=\sum_{n=1,3,5 \ldots}^{\infty} \frac{\mu_{o} M_{n}}{2 \mu_{r}} \frac{n p}{(n p)^{2}-1} \\
& \left(\frac{2\left[\left(\frac{R_{r}}{R_{m}}\right)^{n p+1}-\left(\frac{R_{r}}{R_{m}}\right)^{2 n p}\right]}{\frac{\mu_{r}+1}{\mu_{r}}\left[1-\left(\frac{R_{r}}{R_{s}}\right)^{2 n p}\right]-\frac{\mu_{r}-1}{\mu_{r}}\left[\left(\frac{R_{m}}{R_{s}}\right)^{2 n p}-\left(\frac{R_{r}}{R_{m}}\right)^{2 n p}\right]}\right) \\
& \left(\begin{array}{l}
{\left[\left(\frac{r}{R_{s}}\right)^{n p-1}\left(\frac{R_{m}}{R_{s}}\right)^{n p+1}+\left(\frac{R_{m}}{r}\right)^{n p+1}\right] \cos (n p \theta)\left(\lambda_{0}+\sum_{n=1}^{N_{\lambda}} \lambda_{a n} \cos \left(n Q_{s} \theta\right)\right)} \\
+\left[-\left(\frac{r}{R_{s}}\right)^{n p-1}\left(\frac{R_{m}}{R_{s}}\right)^{n p+1}+\left(\frac{R_{m}}{r}\right)^{n p+1}\right] \sin (n p \theta)\left(\sum_{n=1}^{N_{\lambda}} \lambda_{b} \sin \left(n Q_{s} \theta\right)\right)
\end{array}\right) \\
& B_{s \theta I}(r, \theta)=\sum_{n=1,3,5 \ldots}^{\infty} \frac{\mu_{o} M_{n}}{2 \mu_{r}} \frac{n p}{(n p)^{2}-1} \\
& \left(\frac{2\left[\left(\frac{R_{r}}{R_{m}}\right)^{n p+1}-\left(\frac{R_{r}}{R_{m}}\right)^{2 n p}\right]}{\frac{\mu_{r}+1}{\mu_{r}}\left[1-\left(\frac{R_{r}}{R_{s}}\right)^{2 n p}\right]-\frac{\mu_{r}-1}{\mu_{r}}\left[\left(\frac{R_{m}}{R_{s}}\right)^{2 n p}-\left(\frac{R_{r}}{R_{m}}\right)^{2 n p}\right]}\right) \\
& \left(\begin{array}{l}
{\left[-\left(\frac{r}{R_{s}}\right)^{n p-1}\left(\frac{R_{m}}{R_{s}}\right)^{n p+1}+\left(\frac{R_{m}}{r}\right)^{n p+1}\right] \sin (n p \theta)\left(\lambda_{0}+\sum_{n=1}^{N_{\lambda}} \lambda_{a n} \cos \left(n Q_{s} \theta\right)\right)} \\
-\left[\left(\frac{r}{R_{s}}\right)^{n p-1}\left(\frac{R_{m}}{R_{s}}\right)^{n p+1}+\left(\frac{R_{m}}{r}\right)^{n p+1}\right] \cos (n p \theta)\left(\sum_{n=1}^{N_{\lambda}} \lambda_{b} \sin \left(n Q_{s} \theta\right)\right)
\end{array}\right)
\end{aligned}
$$

\section{Modeling of slotted stator in PMBLAC}

Slotted stator is most commonly used in the construction of PMBLAC. Motor coils are wound in the stator slots, resulting in slot openings which can cause cogging torque. In analytical sub-domain modelling, PMBLAC can be modelled by having four regions (full sub-domain) or only two regions (semi sub-domain). The latter only considers the magnet and airgap regions; therefore, the effect of stator slotting is accounted for using conformal transformation. It is based on multiplying the relative permeance function with the airgap magnetic fields of the slot-less PMBLAC [16-21]. The results of this study were able to provide the approximate fields in the slotted airgap only for radial component of the flux density. The tangential component was not included in the solutions even though the conformal transformation was used. A complete analytical model for slotted PMBLAC is described in detail by applying complex nature of conformal transformation, and defined the relative permeance function as a complex number [22]. The model was able to calculate both radial and tangential components of the airgap magnetic field for the slotted PMBLAC. For the internal rotor slotted PMBLAC, the magnetic fields at mid-airgap for radial and tangential components are shown above as (5) and (6) respectively [23, 24].

There are two operating conditions for PMBLAC, ie open-circuit condition and on-load condition. During open-circuit condition, there is no current flow in the stator coils, and the field is only contributed by PM mounted on the rotor core. When the rotor is rotated, the interaction between the rotor magnets and the stator slot open- ings will result in cogging torque. It can contribute to motor noise and vibration; therefore, it should be minimized as much as possible. The phase back-emf can be obtained during the open-circuit condition using (7) [25]. While, the cogging torque is determined using (8). During on-load condition, currents are excited in the stator coils, and the total magnetic field is contributed by the rotor magnets and armature reaction field. The output power and output torque are determined using (9) and (10), respectively. Then, the input power is estimated using (11).

$$
\begin{gathered}
E_{\mathrm{rms}}=\omega K_{\mathrm{p}} K_{\mathrm{d}} N_{\mathrm{t}} \phi \\
T_{\mathrm{cog}}=\frac{I_{\mathrm{s}} r_{\mathrm{mid}}^{2}}{\mu_{0}} \int_{0}^{2} \pi B_{\mathrm{r}} B_{\theta} \mathrm{d} \theta \\
P_{\mathrm{o}}=3 E_{\mathrm{rms}} I_{\mathrm{rms}} \\
T_{\mathrm{o}}=\frac{3 E_{\mathrm{rms}} I_{\mathrm{rms}} p_{\mathrm{pair}}}{2 \pi f_{\mathrm{e}}} \\
P_{\mathrm{i}}=3\left(E_{\mathrm{rms}} I_{\mathrm{rms}}+I_{\mathrm{rms}}^{2} R_{\varnothing}\right)
\end{gathered}
$$

where, $\omega$ is the electrical angular frequency, $K_{\mathrm{p}}$ is the pitch factor, $K_{\mathrm{d}}$ is the distribution factor, $N_{\mathrm{t}}$ is the winding turns per phase, and $\varphi$ is the total flux entering in one pole pitch, $r_{\text {mid }}$ is the mid radius of the airgap, 0 is the permeability of free space, $\theta$ is the rotor angular position in mechanical degree, while $B_{\mathrm{r}}$ and $B_{\theta}$ are the radial and tangential components for slotted airgap flux density distributions, $E_{\mathrm{rms}}$ is the rms induced backemf per phase, $I_{\text {rms }}$ is the rms phase current, $R_{\varnothing}$ is the phase winding resistance, $p_{\text {pair }}$ is pole-pair number, and 
$f_{\mathrm{e}}$ is the electrical frequency. Due to certain parameters and their value selections for PMBLAC, the optimized performance of the PMBLAC cannot be easily achieved. An optimization algorithm can solve this issue by intelligently searching the optimized parameter values after being provided with the minimum and maximum values for each parameter.

\section{Multi-objective optimization algorithm}

Non-linear multi-objective algorithm can solve global optimization problems [26]. It is not guaranteed that the optimal solutions are ever found, but there is high possibility that a close optimal solution will be determined. Many optimization algorithms can be used, for example genetic algorithm (GA), simulate annealing (SA), differential evolution (DE), and particle swarm optimization (PSO). Many previous studies showed that DE has been widely used due to its capability of outperforming other well-known optimization algorithms [27-34]. Several authors have used model parameters directly as optimization variables, while some authors used ratios of model parameters as optimization variables. Constraint functions are derived from different electromagnetic, thermal, mechanical, manufacturing, economic or standard limits, such as maximum flux density in stator tooth, maximum PM temperature, maximum stress in the IPM rotor bridge, minimum dimensions of magnet, maximum cost of the active material, maximum noise and others. Traditional approach for handling constraint functions is by using penalty functions that penalize the solutions which violate constraints. This principle is implemented in the form of weighted sums which modify each objective function. The terms of cost function and fitness function are similar to objective function. Various objective functions can be used depending on field of applications. Some of the common objective functions in single optimization are to minimize material cost, maximize torque per volume, or maximize torque per weight. When dealing with multi-objective optimization, the use of Paretooptimality-based algorithms is particularly adapted to the industrial framework. They do not lead to single and definitive optimal solution, but to a large set of Paretooptimal solutions so that a degree of freedom is still available at the end of optimization process. An optimization technique is used to solve a non-linear multi-objective problem to determine the optimized parameter setting for certain design parameter so that an expected outcome is achieved. The optimal design search is divided into three categories: (a) deterministic method using scalar objective and fitness function with a unique solution; (b) stochastic method using scalar objective and fitness function with a unique solution or; (c) stochastic method using vector objective with a set of satisfactory/good solution [35]. Sequential Unconstrained Minimization Technique (SUMT), Error-Based Optimization Search (EB), Hooke-Jeeves (HJ), Interval Branch and Bound Method
(IBB), Interior Reflective Newton Method (IRN), combination Sub-problem Approximation and, First-Order Method $(\mathrm{SA}+\mathrm{FO})$, and Inverse Problem Method (IP) are examples of deterministic optimization method. Genetic Algorithm (GA), Simulate Annealing (SA), Particle Swarm Optimization (PSO), Auto Tune PSO, Differential Evolution (DE), and other methods which use combination of algorithm such as GA + Competitive Learning and Bacteria Foraging (BF), are the examples of scalar objective stochastic optimization method. Meanwhile, other methods, namely Multi-objective GA (MOGA), Multiobjective PSO (MOPSO), Multi-objective DE (MODE), DOE-based Multi-objective Methods using Taguchi, and VEKOPT using Gaussian-based, are the examples of vector objective stochastic optimization method. An optimization work using analytical sub-domain with PSO has also been carried out. The cogging torque of PMBLAC was optimized using analytical sub-domain with modified PSO and the radial component of magnetic flux as the constraint [36]. Another machine parameter optimized was the torque ripple using analytical sub-domain with PSO [37].

\section{Differential evolution optimization}

Differential evolution (DE) is one of the artificial intelligent algorithms that has originated from genetic algorithm family. It has four design processes, namely population, mutation, crossover, and selection [31-34]. It is a population based on optimization method. It begins with a randomly initiated population of $N p \quad D$-dimensional real-valued parameter vectors. Each vector, also known as genome/chromosome, forms a candidate solution to the multi-dimensional optimization problem. The $i$-th vector of the population at the current generation can be represented as shown in (12). Each parameter has minimum and maximum bounds as shown in (13) and (14), respectively [33, 34].

$$
\begin{aligned}
\mathbf{x}_{i, g} & =\left[x_{1, g}, x_{2, g}, x_{3, g}, \ldots x_{D, g}\right], \quad x \in R^{D} \\
\mathbf{x}_{i, \min } & =\left[x_{1, \min }, x_{2, \min }, x_{3, g}, \ldots x_{D 1, g}\right], \\
\mathbf{x}_{i, g} & =\left[x_{1, \max }, x_{2, \max }, x_{3, \max }, \ldots x_{D 1, \max }\right] .
\end{aligned}
$$

After initialization, DE creates a donor vector $V_{i, g}$ corresponding to each population member $X_{i, g}$ in the current generation through mutation. Five mutation strategies implemented in the public-domain DE codes are shown in (15) to $(19)[33,34] . F$ is a constant parameter called mutation scale factor

$$
\begin{aligned}
& \text { DE/rand } / 1: \quad \boldsymbol{V}_{i, g}=\boldsymbol{X}_{\mathrm{ro}, \mathrm{g}}+\boldsymbol{F} \cdot\left(\boldsymbol{X}_{\mathrm{r} 1, \mathrm{~g}}-\boldsymbol{X}_{\mathrm{r} 2, \mathrm{~g}}\right) \\
& \text { DE/best/1: } \quad \boldsymbol{V}_{i, g}=\boldsymbol{X}_{\mathrm{best}, \mathrm{g}}+\boldsymbol{F} \cdot\left(\boldsymbol{X}_{\mathrm{r} 1, \mathrm{~g}}-\boldsymbol{X}_{\mathrm{r} 2, \mathrm{~g}}\right) \\
& \text { DE/target-to-best } / 1: \\
& \boldsymbol{V}_{i, g}=\boldsymbol{X}_{i, \mathrm{~g}}+\boldsymbol{F} \cdot\left(\boldsymbol{X}_{\text {best }, \mathrm{g}}-\boldsymbol{X}_{i \mathrm{~g}}\right)+\boldsymbol{F} \cdot\left(\boldsymbol{X}_{\mathrm{r} 1, \mathrm{~g}}-\boldsymbol{X}_{\mathrm{r} 2, \mathrm{~g}}\right)
\end{aligned}
$$


Table 1. Initial machine parameters for 15-slot/10-pole PMBLAC

\begin{tabular}{lccccc}
\hline Parameters & Symbols & Values & Parameters & Symbols & Values \\
Pole pairs number & $p$ & 5 & Magnet remanence, $\mathrm{T}$ & $B_{\mathrm{r}}$ & 1.12 \\
Slot number & $Q_{\mathrm{s}}$ & 15 & Saturation Magnetic Flux, $\mathrm{T}$ & $B_{\mathrm{max}}$ & 1.6 \\
Magnet arc-pole pitch ratio & $\alpha_{\mathrm{p}}$ & 1.0 & Relative recoil permeability & $\mu_{\mathrm{r}}$ & 1.05 \\
Air gap length, mm & $h_{\mathrm{g}}$ & 1.0 & Rated Speed, rpm & $r_{\mathrm{m}}$ & 600 \\
Magnet radial thickness, $\mathrm{mm}$ & $h_{\mathrm{m}}$ & 3.0 & Mid air gap radius, mm & $R_{\mathrm{g}}$ & 33.8 \\
Rotor surface radius, mm & $R_{\mathrm{r}}$ & 30.3 & Slot opening width, $\mathrm{mm}$ & $b_{\mathrm{o}}$ & 2.0 \\
Magnet surface radius, $\mathrm{mm}$ & $R_{\mathrm{m}}$ & 33.3 & Tooth body width, mm & $w_{\text {tb }}$ & 7.45 \\
Stator inner radius, mm & $R_{\mathrm{si}}$ & 34.3 & Stator yoke thickness, mm & $w_{\mathrm{sy}}$ & 3.72 \\
Stator outer radius, mm & $R_{\mathrm{so}}$ & 60.0 & Tooth teeth height, mm & $w_{\mathrm{tt}}$ & 2.87 \\
Stack length, mm & $l_{\mathrm{s}}$ & 50.0 & Number of turns/coil, turns & $N_{\mathrm{c}}$ & 30 \\
\hline
\end{tabular}

\section{$\mathrm{DE} / \mathrm{best} / 2$ :}

$\boldsymbol{V}_{i, g}=\boldsymbol{X}_{\text {best }, \mathrm{g}}+\boldsymbol{F} \cdot\left(\boldsymbol{X}_{\mathrm{r} 1, \mathrm{~g}}-\boldsymbol{X}_{\mathrm{r} 2, \mathrm{~g}}\right)+\boldsymbol{F} \cdot\left(\boldsymbol{X}_{\mathrm{r} 3, \mathrm{~g}}-\boldsymbol{X}_{\mathrm{r} 4, \mathrm{~g}}\right)$

$\mathrm{DE} / \mathrm{rand} / 2$ :

$\boldsymbol{V}_{i, g}=\boldsymbol{X}_{\mathrm{r} 1, \mathrm{~g}}+\boldsymbol{F} \cdot\left(\boldsymbol{X}_{\mathrm{r} 2, \mathrm{~g}}-\boldsymbol{X}_{\mathrm{r}, 3 \mathrm{~g}}\right)+\boldsymbol{F} \cdot\left(\boldsymbol{X}_{\mathrm{r} 4, \mathrm{~g}}-\boldsymbol{X}_{\mathrm{r} 5, \mathrm{~g}}\right)$

To enhance the potential diversity of the population, a crossover operation is run after generating the donor vector through mutation. The common binomial crossover is applied on each D variables whenever a randomly generated number between 0 and 1 is less than or equal to the crossover constant $\mathrm{Cr}$ value as shown in $(20)$ [33, 34].

$$
\boldsymbol{U}_{i, g}=u_{j, i, g}=\left\{\begin{array}{l}
v_{j, i, g} \text { if } r_{j} \leq C_{\mathrm{r}} \text { or } j=j_{\mathrm{rand}} \\
x_{j, i, g} \text { if } r_{j}>C_{\mathrm{r}} \\
j=1, \ldots, n
\end{array}\right.
$$

The selection step is to determine whether the target or the trial vector survives to the next generation. The selection operation is shown in $(21)[32,33]$

$$
\boldsymbol{X}_{i, g+1}=\left\{\begin{array}{l}
\boldsymbol{U}_{i, g} \text { if } f\left(\boldsymbol{U}_{i, g}\right) \leq f\left(\boldsymbol{X}_{i, g}\right) \\
\boldsymbol{X}_{i, g} \text { if } f\left(\boldsymbol{U}_{i, g}\right)>f\left(\boldsymbol{X}_{i, g}\right)
\end{array}\right.
$$

The suggested control parameter for mutation scale factor $F$ is from 0.5 to 1.0, the crossover constant $C_{\mathrm{r}}$ is from 0.8 to 1.0 , and the population size $N_{\mathrm{p}}$ is approximately equal to ten times the variables/parameters [33]. Based on the literature survey, the analytical sub-domain and DE will have better results compared to PSO and GA. Due to that, in this paper, a research on the optimization of PMBLAC using an Analytical Sub-Domain with Differential Evolution Algorithm called as ASDEA is proposed, applied, and described, which has never been done by other researchers so far.

\section{Research methodology}

\subsection{1 initial machine parameters using sizing equations}

A typical 2-D model of PMBLAC is represented in Fig. 4 with associated machine parameters to be identified. In this research, a three-phase, 15-slot/10-pole PMBLAC was chosen with concentrated winding configuration and surface-mounted $\mathrm{NdFeB}$ permanent magnet that has radial magnetization pattern. The core was made of silicon-steel. Other parameters are given in Tab. 1.

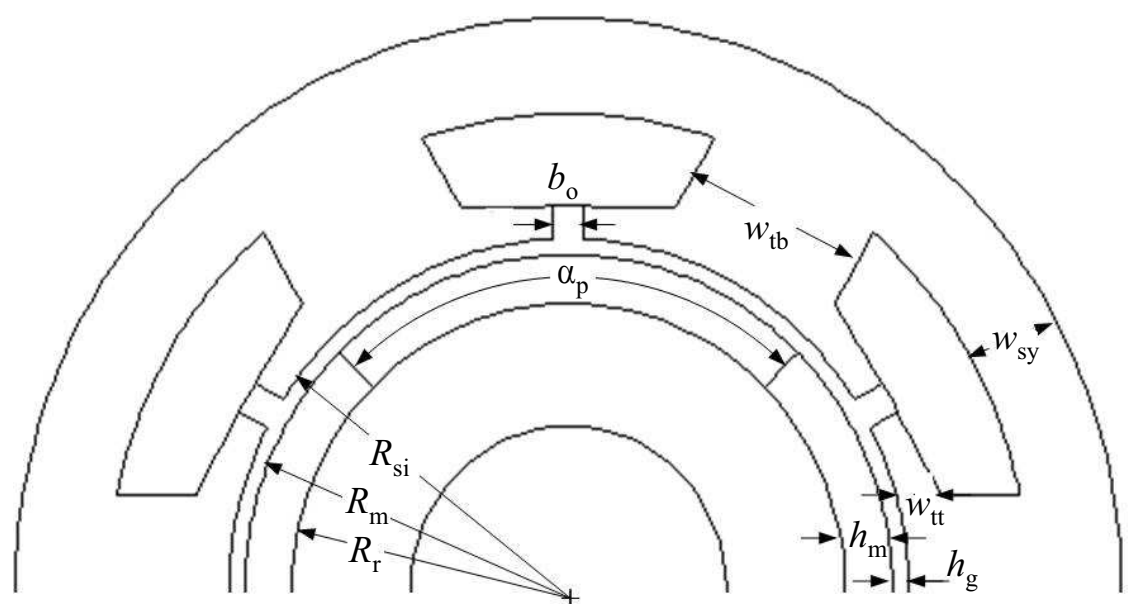

Fig. 2. Typical 2-D model of PMBLAC 
To identify the initial value of machine geometric parameters, motor sizing (22) to (30) were applied [38]

$$
\begin{gathered}
\frac{D_{\mathrm{si}}}{D_{\mathrm{so}}}=\frac{-b-\sqrt{b^{2}-4 a c}}{2 a} \\
a=2\left[\frac{k \pi}{p}\left(\frac{k \pi}{p}+2\right)\left(\frac{B_{g}}{B_{\max }}\right)^{2}+2 \frac{B_{g}}{B_{\max }}-1\right] \\
b=\frac{3}{2}\left[-2\left(\frac{k \pi}{p}+1-2 \frac{w_{\mathrm{tt}}}{D_{\mathrm{so}}}\right)\left(\frac{B_{g}}{B_{\max }}\right)-4 \frac{w_{\mathrm{tt}}}{D_{\mathrm{so}}}\right] \\
c=1-4\left(\frac{w_{\mathrm{tt}}}{D_{\mathrm{so}}}\right)^{2} \\
k=\frac{1}{3} \\
B_{g}=\frac{B_{\mathrm{r}}}{1-\mu_{0} \frac{h_{g}}{h_{m}}} \\
w_{\mathrm{tb}}=\frac{2 \pi R_{\mathrm{si}}}{Q_{\mathrm{s}}}\left(\frac{B_{g}}{B_{\mathrm{max}}}\right) \\
w_{\mathrm{sy}}=w_{\mathrm{tb}} / 2 \\
w_{\mathrm{tt}}=\frac{2 \pi R_{\mathrm{si}}-w_{\mathrm{tb}} Q_{\mathrm{s}}}{2 Q_{\mathrm{s}}}\left(\frac{B_{g}}{B_{\max }}\right)
\end{gathered}
$$

where $D_{\mathrm{si}}$ is stator inner diameter, $D_{\text {so }}$ is stator outer diameter, $k$ is a constant for concentrated winding, $B_{g}$ is average airgap magnetic flux density and $B_{\max }^{*}$ is maximum flux density in tooth end. There are five machine parameters selected for optimization: magnet arc-polepitch ratio $-\alpha_{\mathrm{p}}$, magnet thickness $-h_{\mathrm{m}}$, air-gap length $-h_{\mathrm{g}}$, slot opening width $-b_{\mathrm{o}}$, and stator inner radius $R_{\mathrm{si}}$ with boundary constraints as shown in Tab. 2 . The multi-objectives are in creating machine with the highest efficiency, highest output torque, lowest total harmonics distortion of phase back-emf, and lowest cogging torque.

Table 2. Boundary constraints of selected machine parameters

\begin{tabular}{lcc}
\hline Parameters & Symbols & Values \\
Magnet arc-pole pitch ratio & $\alpha_{\mathrm{p}}$ & $0.5-1.0$ \\
Air gap length, mm & $h_{\mathrm{g}}$ & $0.5-1.0$ \\
Magnet radial thickness, mm & $h_{\mathrm{m}}$ & $2.0-3.0$ \\
Slot opening width, mm & $b_{\mathrm{o}}$ & $1.8-2.2$ \\
Stator inner radius, $\mathrm{mm}$ & $R_{\mathrm{si}}$ & $30-36$ \\
\hline
\end{tabular}

The research started by determining the machine geometry using sizing equations. After that, analytical subdomain model was applied to identify the magnetic flux density at mid-airgap, phase back-emf, and electromagnetic torque. Next, machine with selected initial geometry was optimized using differential evolution algorithm. This algorithm was run through four stages, namely population, mutation, crossover, and selection. It was kept running until it reached the required objective functions such as the highest efficiency, highest output torque, lowest total harmonics distortion of phase back-emf, and lowest cogging torque. Then, the optimized machine was built and modelled using finite element analysis software which was Opera2D to validate the optimized machine model computed from ASDEA.

\section{Results and discussion}

The Pareto-fronts of objection function for efficiencyoutput torque versus phase back-emf THDv and objective function for efficiency-output torque versus cogging torque, are given in Figs. 5 and 6, respectively. The optimization process should satisfy the four objectives, $i e$ highest efficiency, highest output torque, lowest phase back-emf total harmonic distortions, THDv, and lowest cogging torque. From ASGA, the selected points were 92.54\% efficiency, $4.41 \mathrm{Nm}$ output torque, $4.96 \%$ THDv, and $0.34 \mathrm{Nm}$ cogging torque. While from ASDEA, the selected points were $93.09 \%$ efficiency, $4.48 \mathrm{Nm}$ output torque, $5.85 \%$ THDv, and $0.37 \mathrm{Nm}$ cogging torque. Each selected point has their own optimized machine parameters: magnet arc pole-pitch ratio ?p, slot opening width $b_{\mathrm{o}}$, magnet thickness $h_{\mathrm{m}}$, airgap length $h_{\mathrm{g}}$, and stator inner radius $R_{\mathrm{si}}$, as listed in Tab. 3 , where $A_{\text {slot }}$ is the winding slot area, $R_{981}$ is coil phase resistance, $P_{\text {loss }}$ is power loss, $P_{\text {ave }}$ is the average power, $P_{\text {in }}$ is the input power, $T_{\text {ave }}$ is the average torque, $T_{\text {ripple }}$ is the torque ripple, $T_{\operatorname{cog}}$ is the cogging torque, and $\eta$ is efficiency of the motor. The selected point in the Pareto-front chart for optimized machine parameters from ASDEA was used to build the FE model to verify the output.

From the difference between ASGA and ASDEA (denoted as ASGA-ASDEA, $\Delta 1$ ), it is observed that ASGA has longer computational time compared to ASDEA. This was due to the genetic algorithm genomes production and its mutation factor scheme. ASDEA has computational time approximately $77 \%$ faster than ASGA, indicating a good factor in reducing the time to design the motor. Normally, using finite element (FE) software such as Opera2D, longer computational time is required. For 15slot/10-pole PMBLAC, for instance, computational time of about two hours is needed for an experienced user to build the motor model and obtain the FE results from a single value machine parameter. If five machine parameters are to be varied, and assuming each parameter has variation of ten-point values, the FE software will take approximately about 100 hours to complete. Yet still the best results of machine parameters to be obtained were uncertain because the value setting for each machine parameter was fixed at discrete points. However, intelligent optimization algorithm could mitigate this issue. Those repetitive FE modelling which may be considered as redundancy work can be lessened by using optimization technique. The 15-slot/10-pole PMBLAC machine initially used copper wire with 50 turns per coil, 
Table 3. Comparison of optimized parameters for 15-slot/10-pole PMBLAC

\begin{tabular}{lcccccc} 
Parameters & Initial & ASGA & ASDEA & $\begin{array}{c}\text { ASGA- } \\
\text { ASDEA } \Delta \text { 1, } \%\end{array}$ & $\begin{array}{c}\text { Initial- } \\
\text {-ASGA } \Delta 2, \%\end{array}$ & $\begin{array}{c}\text { Initial- } \\
\text {-ASDEA } \Delta, \%\end{array}$ \\
\hline time, hrs & - & 5.29 & 1.21 & -77.16 & - & - \\
$\alpha_{\mathrm{p}}$ & 1.00 & 0.80 & 0.80 & -0.48 & -19.88 & -20.26 \\
$b_{\mathrm{o}}, \mathrm{mm}$ & 2.00 & 1.95 & 1.85 & -5.03 & -2.50 & -7.40 \\
$h_{\mathrm{m}}, \mathrm{mm}$ & 3.00 & 2.88 & 2.60 & -9.68 & -3.93 & -13.23 \\
$h_{\mathrm{g}}, \mathrm{mm}$ & 1.00 & 0.99 & 0.86 & -13.54 & -1.00 & -14.40 \\
$R_{\text {si }}, \mathrm{mm}$ & 34.30 & 31.25 & 31.11 & -0.44 & -8.90 & -9.30 \\
$A_{\text {slot }}, \mathrm{mm} 2$ & 231.658 & 278.24 & 277.91 & -0.12 & +20.15 & +20.01 \\
$w_{\text {tb }}, \mathrm{mm}$ & 7.40 & 6.70 & 6.80 & +1.49 & -9.46 & -8.11 \\
$w_{\text {sy }}, \mathrm{mm}$ & 3.70 & 3.40 & 3.40 & 0.0 & -8.11 & -8.11 \\
$w_{\text {tt }}, \mathrm{mm}$ & 2.90 & 2.60 & 2.60 & 0.0 & -10.34 & -10.34 \\
$E_{\mathrm{rms}}, \mathrm{V}$ & 28.58 & 25.55 & 25.96 & +1.58 & -10.57 & -9.16 \\
$E_{\mathrm{rms}} \mathrm{THDv}, \%$ & 18.24 & 4.96 & 5.86 & +18.18 & -72.81 & -67.87 \\
$R_{981}, 8486$ & 0.71 & 0.56 & 0.56 & 0.0 & -21.33 & -21.33 \\
$P_{\text {loss }}, \mathrm{W}$ & 26.54 & 20.88 & 20.88 & 0.0 & -21.33 & -21.33 \\
$P_{\text {ave }}, \mathrm{W}$ & 325.06 & 277.42 & 282.11 & +1.69 & -14.92 & -13.48 \\
$P_{\text {in }}, \mathrm{W}$ & 351.60 & 298.30 & 302.99 & +1.57 & -15.16 & -13.83 \\
$T_{\text {ave }}, \mathrm{Nm}$ & 5.18 & 4.42 & 4.49 & +1.69 & -14.69 & -13.25 \\
$T_{\text {ripple }}, \mathrm{Nm}$ & 0.62 & 0.22 & 0.25 & +15.00 & -64.38 & -59.04 \\
$T_{\text {cog }}, \mathrm{Nm}$ & 0.58 & 0.34 & 0.38 & +9.72 & -40.59 & -34.81 \\
$\eta, \%$ & 91.97 & 93.00 & 93.11 & +0.11 & +1.12 & +1.24 \\
\hline
\end{tabular}

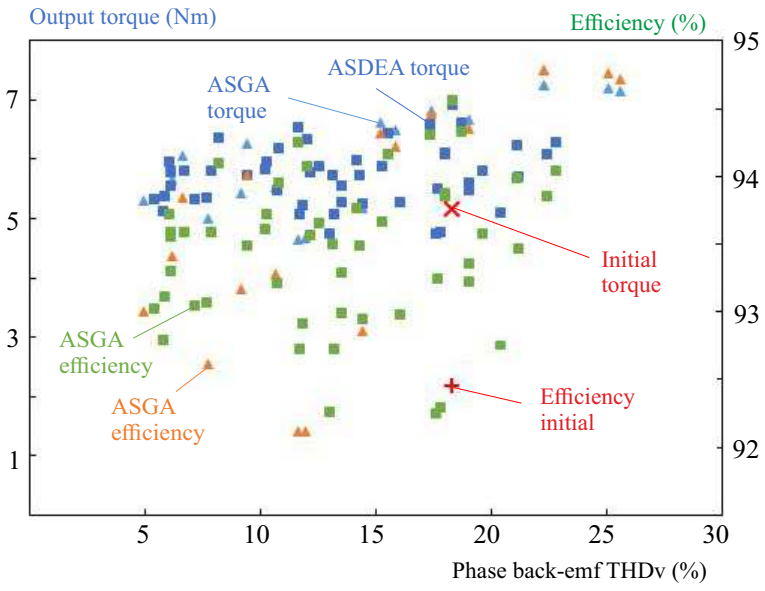

Fig. 3. Pareto-front for efficiency-output torque versus phase backemf THDv

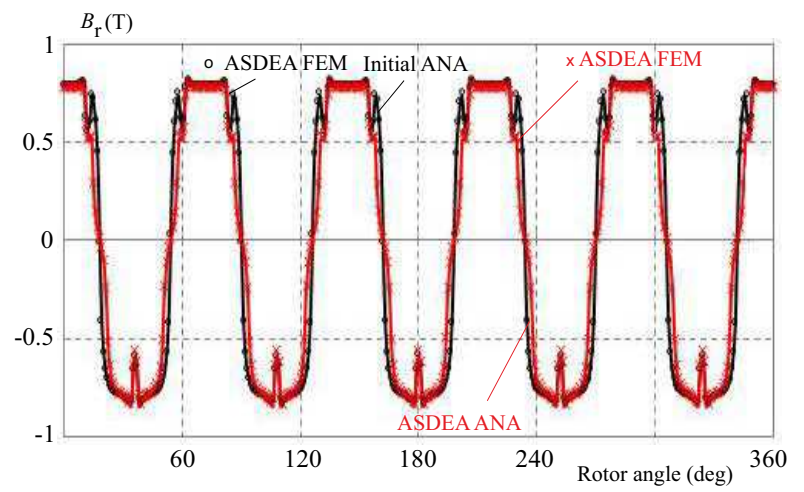

Fig. 5. Magnetic flux density distributions at mid-airgap, radial component

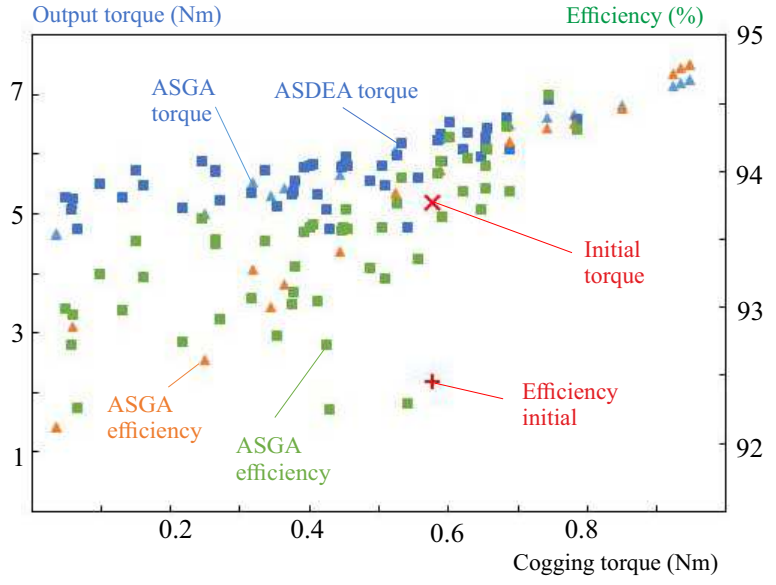

Fig. 4. Pareto-front for efficiency-output torque versus cogging torque

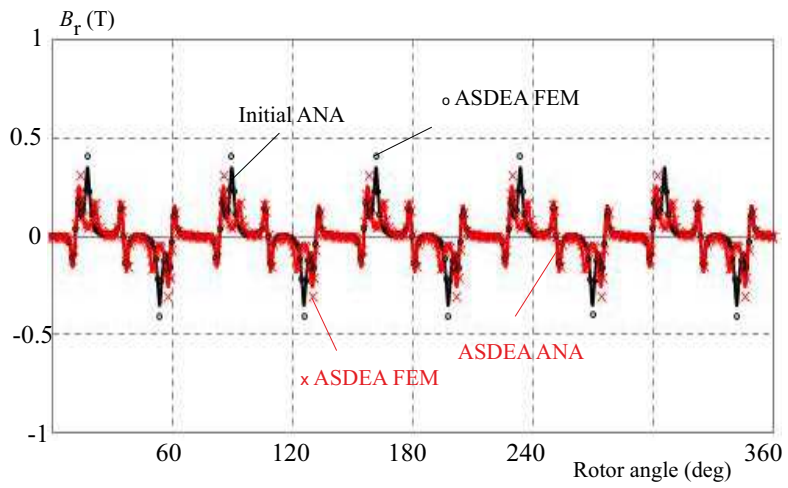

Fig. 6. Magnetic flux density distributions at mid-airgap, tangential component 


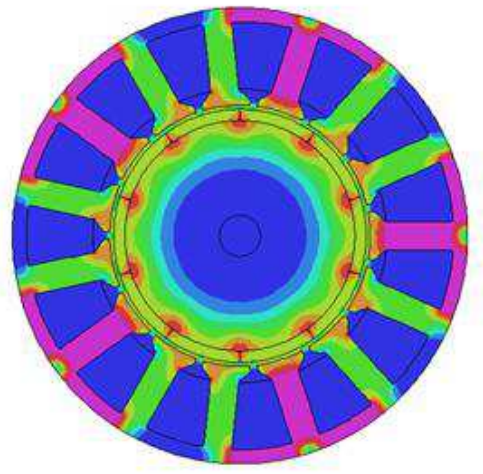

0

0.762

1.523

Fig. 7. Magnetic flux density before optimized

with $5 \mathrm{~A}$ peak current excited into the stator coil to generate an average power of $325.06 \mathrm{~W}$. The average torque was $5.18 \mathrm{Nm}$ and the efficiency was $91.97 \%$. Referring to Initial-ASDEA $\Delta 3$ in Tab. 3 , the machine has $67.8 \%$ reduction in phase back-emf THDv, $34.8 \%$ reduction in cogging torque, $59 \%$ reduction in torque ripple, $13.4 \%$ reduction in average power, $13.2 \%$ reduction in average torque, and $1.2 \%$ increase in efficiency. The cogging torque decrease is due to the reduction of magnet arc. The phase back-emf is slightly reduced due to the smaller stator inner radius, resulting in slightly lower output power and torque compared to initial 15-slot/10-pole PMBLAC.

In ASDEA and ASGA, since the winding slot area, Aslot is increased approximately by $20 \%$, with a packing factor of $40 \%$, the phase resistance is lower which contributed to reducing the power loss in the machine. The other losses such as eddy current loss and core loss are considered negligible since the machine is only operated at low rated speed of 600rpm. Fig. 7 and Fig. 8 represent the radial and tangential component for magnetic flux distribution at mid-airgap. The slotting effect was reduced due to $7.4 \%$ reduction in slot opening width, $b_{\mathrm{o}}$. In these figures, the legend Initial ANA means the analytical

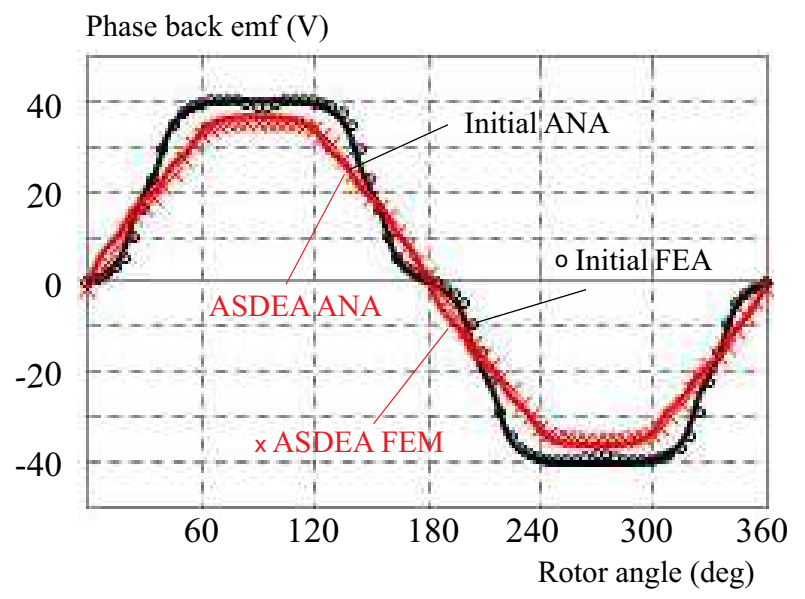

Fig. 9. Phase back-emf

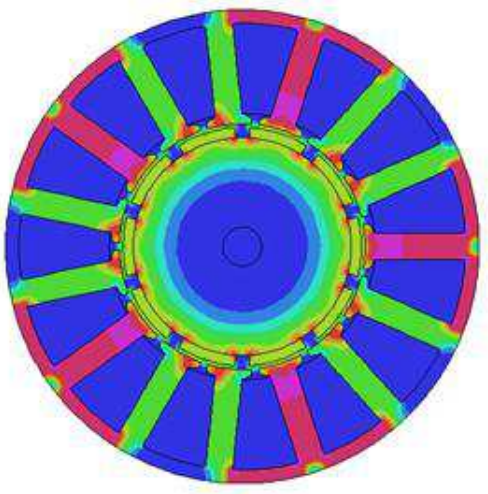

0.764

Fig. 8. Magnetic flux density after optimized

results of the motor using initial parameters. Initial FEM indicates the results from 2D FE motor model also using the initial parameters. Whereas, ASDEA ANA means the results from ASDEA optimization technique, while ASDEA FEM is the results from 2D FE motor model built using the optimal parameters from ASDEA.

The magnetic flux density in the machine, as illustrated in Figs. 9 and 10, will not saturate when operating under on-load condition. The maximum magnetic flux density in the stator tooth body is below the saturation level, 1.6T. A slight reduction of magnetic flux is observed in the tooth body width when the machine has been optimized. This is due to reduction of magnet arc pole-pitch ratio. The magnitudes of phase back-emf and cogging torque have reduced by $8.1 \%$ and $54.1 \%$ as shown in Fig. 11 and Fig. 12, respectively. However, the shape of phase back-emf waveform is more sinusoidal now. This leads to lower output torque ripple as shown in Fig.13.

Finally, the optimized PMBLAC based on ASDEA produces smaller volume of stator core and magnets which can contribute to the reduction of machine active materials. Furthermore, the optimized motor also achieves $27.1 \%$ reduction of copper loss and $1.1 \%$ increase

Cogging torque $(\mathrm{Nm})$

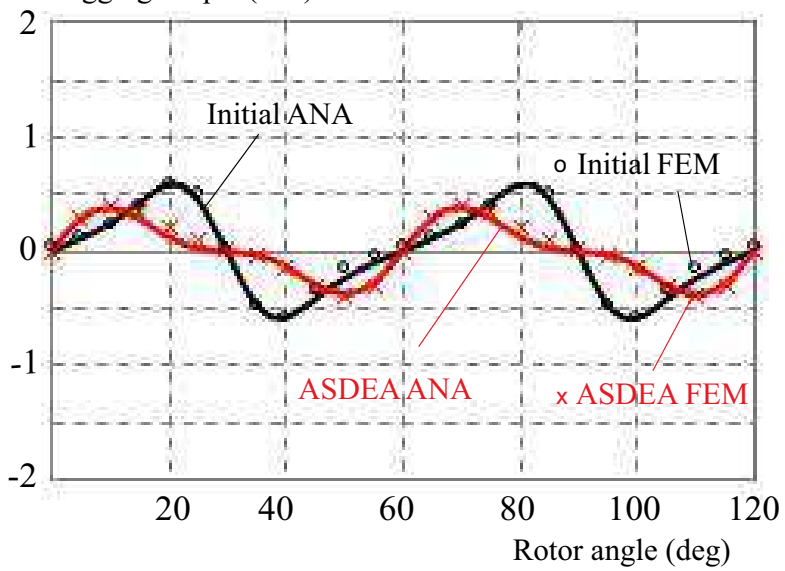

Fig. 10. Cogging torque 
in efficiency compared to that of initial PMBLAC design. It is also noted that ASDEA is better than ASGA since the former only required 1.2 hours to complete the computation compared to ASGA that needed 5.3hours. ASDEA optimization technique is suitable in optimizing PMBLAC with better results and shorter time compared to ASGA.

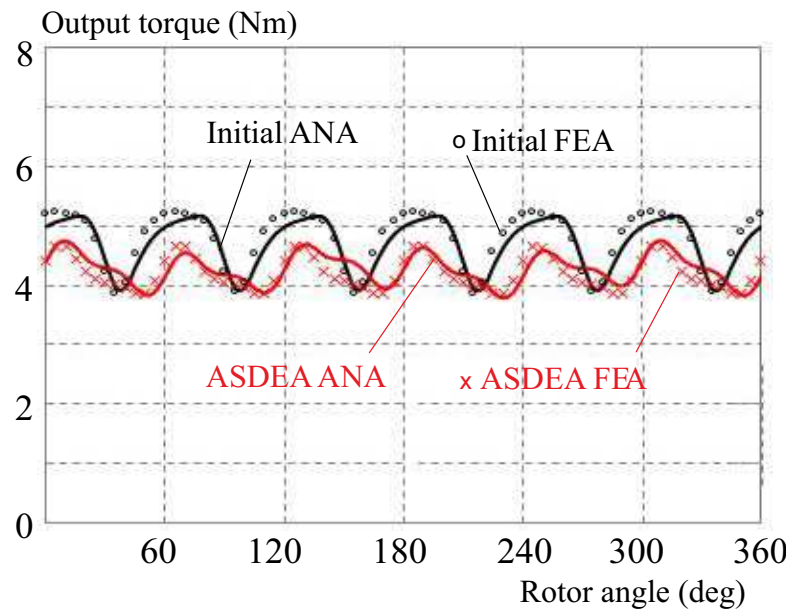

Fig. 11. Output torque

\section{Conclusion}

The Analytical Sub-Domain model with Differential Evolution Algorithm (ASDEA) has been described and presented. The ASDEA was compared with another optimization algorithm such as ASGA. It is proven that ASDEA is better than ASGA since the former was able to optimize with shorter computing time and higher accuracy for the three-phase surface-mounted permanent magnet brushless AC machines (PMBLAC). The amount of repetitive FE modelling may be minimized by using ASDEA technique during initial design stage of the machine. ASDEA could greatly provide benefits to the machine designer in developing electric machines with faster, accurate and cost effective solution.

\section{Acknowledgements}

The authors would like to sincerely thank Universiti Sains Malaysia for the financial support in this research work from RUI Grant Scheme under project number 1001/PELECT/801402, and Ministry of Higher Education Malaysia for the financial support under FRGS grant scheme 203/PELECT/6071328.

\section{REFERENCES}

[1] Z. Q. Zhu and C. C. Chan, "Electrical machine topologies technologies for electric, hybrid, IEEE Vehicle Power Propulsion Conference (VPPC'08), Harbin,, pp. 1-6, 2008.

[2] A. M. El-refaie, "Fractional-Slot Concentrated-Windings Synchronous Permanent Magnet Machines: Opportunities Challenges, IEEE Transactions on Industrial Electronics, ol. 57, no. 1, pp. 107-121, January 2010.
[3] T. Finken, M. Hombitzer, and K. Hameyer, "Study comparison of several permanent-magnet excited rotor types regarding their applicability in electric vehicles, Emobility - Electrical Power Train, pp. 1-7, 8-9 November 2010.

[4] J. Baek, M. M. Rahimian, and H. A. Toliyat, "Optimal design of PM assisted synchronous reluctance generators using lumped parameter model Differential Evolution Strategy, IEEE Energy Conversion Congress Exposition (ECCE 2009), pp, 2453-2459, 20-24 Sept, , 2009.

[5] H. Jussila, P. Salminen, M. Niemela, and J. Pyrhonen, "Guidelines for Designing Concentrated Winding Fractional Slot Permanent Magnet Machines, International Conference on Power Engineering Energy Electrical Drives, (POWERENG 2007), pp. 191-194, 12-14 April 2007.

[6] Y. Duan and D. M. Ionel, "A Review of Recent Developments in Electrical Machine Design Optimization Methods With a Permanent-Magnet Synchronous Motor Benchmark Study, IEEE Transactions on Industry Applications, ol. 49, no. 3 pp. 1268-1275, May-June 2013.

[7] M. Yilmaz and P. T. Krein, "Capabilities of finite element analysis magnetic equivalent circuits for electrical machine analysis design, IEEE Power Electronics Specialists Conference (PESC 2008), Rhodes,, pp. 4027-4033, 2008.

[8] G. Y. Sizov, D. M. Ionel, and N. A. O. Demerdash, "A review of efficient FE modeling techniques with applications to PM AC machines, IEEE Power Energy Society General Meeting San Diego, CA, pp. 1-6, 2011.

[9] M. Yilmaz, "Limitation/capabilities of electric machine technologies modeling approaches for electric motor design analysis in plug-in electric, Renewable Sustainable Energy Reviews, ol. 52, pp. 80-99, 2015.

10] T. Lubin, S. Mezani, and A. Rezzoug, "2-D Exact Analytical Model for Surface-Mounted Permanent-Magnet Motors With Semi-Closed Slots, IEEE Transactions on Magnetics, ol. 47, no. 2, pp. 479-492, February 2011.

11] L. J. Wu, Z. Q. Zhu, D. Staton, M. Popescu, and D. Hawkins, "An Improved Subdomain Model for Predicting Magnetic Field of Surface-Mounted Permanent Magnet Machines Accounting for Tooth-Tips, IEEE Transactions on Magnetics, ol. 47, no. 6, pp. 1693-1704, June 2011.

12] L. J. Wu, Z. Q. Zhu, D. Staton, M. Popescu, and D. Hawkins, "Comparison of analytical models for predicting electromagnetic performance in surface-mounted permanent magnet machines, IEEE Vehicle Power Propulsion Conference (VPPC) Lille, pp. 1-6, 2010.

[13] A. Gilson, S. Tavernier, F. Dubas, D. Depernet, and C. Espanet, "2-D analytical subdomain model for high-speed permanent-magnet machines, 18th International Conference on Electrical Machines Systems (ICEMS) Pattaya,, pp. 1508-1514, 2015.

$14]$ Z. Q. Zhu, L. J. Wu, and Z. P. Xia, "An Accurate Subdomain Model for Magnetic Field Computation in Slotted Surface-Mounted Permanent-Magnet Machines, IEEE Transactions on Magnetics, ol. 46, no. 4, pp. 1100-1115, April 2010.

15] T. L. Tiang, D. Ishak, C. P. Lim, and M. K. M. Jamil, "A Comprehensive Analytical Subdomain Model Its Field Solutions for Surface-Mounted Permanent Magnet Machines, IEEE Transactions on Magnetics, ol. 51, no. 4, pp. 1-14, April 2015.

[16] Y. Yang, X. Wang, R. Zhang, T. Ding, and R. Tang, "The optimization of pole arc coefficient to reduce cogging torque in surface-mounted permanent magnet motors, IEEE Trans, Magn, ol. 42, no. 4, pp. 11351138, April 2006.

[17] J. F. Gieras, "Analytical approach to cogging torque calculation in PM brushless motors, IEEE Int, Electric Machines Drives Conf, IEMDC03, Madison, WI,vol. 2, pp. 815819, Jun 2003.

[18] A. B. Proca, A. Keyhani, A. El-antably, W. Lu, and M. Dai, "Analytical model for permanent magnet motors with surface 
mounted magnets, IEEE Trans, Energy Convers,, ol. 18, no. 3, pp. 386391, September 2003.

[19] X. Wang, Q. Li, S. Wang, and Q. Li, "Analytical calculation of air-gap magnetic field distribution instantaneous characteristics of brushless DC motors, IEEE Trans, Energy Convers,, ol. 18, no. 3, pp. 424432, September 2003.

[20] Z. Q. Zhu and D. Howe, "Instantaneous magnetic field distribution in brushless permanent magnet DC motors. II. Armature-reaction field, IEEE Transactions on Magnetics, ol. 29, no. 1, pp. 136-142, January 1993.

[21] B. Ackermann, J. H. H. Janssen, R. Sottek, and R. I. Van Steen, "New technique for reducing cogging torque in a class of brushless DC motors, IEE Proc, Elect, Power Applicat,vol, 139, no. 4, pp. 315320, July 1992.

[22] A. Damir Zarko Drago Ban Thomas, "Analytical Calculation of Magnetic Field Distribution in the Slotted Air Gap of a Surface Permanent-Magnet Motor Using Complex Relative Air-Gap Permeance, IEEE Trans, on Magnetics, ol. 42, no. 7, pp. 1828-1837, July 2006.

[23] M. Rezal and D. Ishak, "High Efficiency Surface-Mounted Permanent Magnet Machine using Analytical Sub-Domain Particle Swarm Optimization Model, 7 th Postgraduate Colloquium EEPC 2017, Penang, 22-23 November 2017,

[24] M. Rezal and D. Ishak, "Analytical Modeling of Armature Reaction for Surface-Mounted Permanent Magnet Synchronous Motor, in 6 th Postgraduate Colloquium EEPC, Penang, 20-21 December 2016,

[25] M. Rezal, D. Ishak, and W. A. Salah, "Multiobjective design of permanent magnet synchronous machines based on analytical sub-domain particle swarm optimization, IEEE Conference on Energy Conversion (CENCON) Kuala Lumpur,, pp. 230-235, 2017, .

[26] S. Stipetic, W. Miebach, and D. Zarko, "Optimization in Design of Electric Machines: Methodology Workflow, ACEMP - OPTIM - ELECTROMOTION joint conference 2015, http://www, adept-itn, eu/images/Publications/Optimization_in_Design_of Electric_Machines_Methodology_and_Workflow, pdf, [Online: 24 March 2016],

[27] T. Marcic, B. Stumberger, and G. Stumberger, "Differential-evolutionbased parameter identification of a line-start IPM synchronous motor, IEEE Transaction on Industrial Electronics, ol. 61, no. 11, November 2014.

[28] P. Divya, S. Visalakshi, and V. Vijayalakshmi, "Design Optimization of PM AC Machines Using Differential Evolution Computationally Efficient-FEA, International Journal of Advanced Research in Electrical Electronics Instrumentation Engineering, vol, 3,no, 4, May 2014,.

[29] F. Carafini, F. Neri, J. Cheng, and G. Zhang, "Super-fit Multicriteria Adaptive Differential Evolution, IEEE Congress on Evolutionary Computation Cancun, Mexico,, pp. 1678-1685, 20-23 June 2013.

[30] T. Andromeda, A. Yahya, S. Samion, A. Baharom, and N. L. Hashim, "Differential evolution for optimization of PID gain in electrical discharge machining control system, in Transaction on the Canadian Society for Mechanical Engineering, ol. 37, no. 3, 2013.

[31] P. Md Nasar, "A Differential Evolution Approach for Software Testing Effort Allocation, Journal of Industrial Intelligent Information, ol. 1, no. 2, June 2013.
[32] G. Arnob, S. Das, A. Chowdhury, and R. Giri, "An improved differential evolution algorithm with fitness-based adaptation of the control parameters, Information Sciences, ol. 181,no. 18 pp. 3749-3765, September 2011.

33] A. Shamekhi, "An Improved Differential Evolution Optimization Algorithm, International Journal of Research Reviews in Applied Sciences, ol. 15, no. 2, pp. 132-145, May 2013.

34] M. Muetler and O. Bilgin, "Comparison of stochastic optimization methods for design optimization of permanent magnet synchronous motor, Neural Computing Applications, ol. 21, no. 8 , pp. 2049-2056, November 2012.

[35] Y. Duan and D. M. Ionel, "A Review of Recent Developments in Electrical Machine Design Optimization Methods With a Permanent-Magnet Synchronous Motor Benchmark Study, IEEE Transactions on Industry Applications, ol. 49, no. 3, pp. 1268-1275, May-June 2013.

[36] Z. Xue, H. Li, Y. Zhou, N. Ren, and W. Wen, "Analytical Prediction Optimization of Cogging Torque in Surface-Mounted Permanent Magnet Machines With Modified Particle Swarm Optimization, IEEE Transactions on Industrial Electronics, ol. 64, no. 12, pp. 9795-9805, December 2017.

37] H. Guo, Z. Wu, H. Qian, and Z. Sun, "Robust design for the 9-slot 8-pole surface-mounted permanent magnet synchronous motor by analytical method-based multi-objectives particle swarm optimisation, IET Electric Power Applications, ol. 10 no. 2, pp. 117-124, February 2016.

38] Y. Pang, Z. Q. Zhu, and D. Howe, "Analytical determination of optimal split ratio for permanent magnet brushless motors, IEE Proceedings - Electric Power Applications, ol. 153, no. 1, pp. 7-13, 1 January 2006.

Received 17 April 2019

Mohd Rezal Mohamed received the BEng (Hons) degree in electrical and electronics engineering and the MSc in electronic engineering from the Universiti Putra Malaysia, Serdang, Selangor, Malaysia in 2002 and 2008 respectively. He is currently pursuing $\mathrm{PhD}$ degree in electrical machines and drives from the Universiti Sains Malaysia, Penang, Malaysia. He is currently a senior lecturer at the Electrical, Electronics, and Automation Section, Universiti Kuala Lumpur, Malaysian Spanish Institute, Kulim, Kedah, Malaysia. His current research interests include design of permanent magnet synchronous machines and electric vehicles.

Dahaman Ishak received the BSc degree in electrical engineering from Syracuse University, Syracuse, NY, USA, the MSc degree in electrical power from the University of Newcastle Upon Tyne, Newcastle upon Tyne, UK, and the PhD degree from the University of Sheffield, Sheffield, UK, in 1990, 2001 and 2005 respectively. He is currently an Associate Professor with the School of Electrical and Electronic Engineering, Universiti Sains Malaysia, Penang, Malaysia. His current research interests include permanent magnet brushless machines, electrical drives, power electronic converters and renewable energy. 